\title{
Technical note: Mining data from on-farm electronic equipment to identify the time dairy cows spend away from the pen
}

\author{
A. J. Thompson, D. M. Weary, and M. A. G. von Keyserlingk ${ }^{1}$ \\ Animal Welfare Program, Faculty of Land and Food Systems, University of British Columbia, Vancouver, BC, V6T 1Z4, Canada
}

\begin{abstract}
The electronic equipment used on farms can be creatively co-opted to collect data for which it was not originally designed. In the current study, we describe 2 novel algorithms that harvest data from electronic feeding equipment and data loggers used to record standing and lying behavior, to estimate the time that dairy cows spend away from their pen to be milked. Our 2 objectives were to (1) measure the ability of the first algorithm to estimate the time cows spend away from the pen as a group and (2) determine the capability of a second algorithm to estimate the time it takes for individual cows to return to their pen after being milked. To achieve these objectives, we conducted 2 separate experiments: first, to estimate group time away, the feeding behavior of 1 pen of 20 Holstein cows was monitored electronically for 1 mo; second, to measure individual latency to return to the pen, feeding and lying behavior of 12 healthy Holstein cows was monitored electronically from parturition to $21 \mathrm{~d}$ in milk. For both experiments, we monitored the time each individual cow exited the pen before each milking and when she returned to the pen after milking using video recordings. Estimates generated by our algorithms were then compared with the times captured from the video recordings. Our first algorithm provided reliable penbased estimates for the minimum time cows spent away from the pen to be milked in the morning [coefficient of determination $\left.\left(\mathrm{R}^{2}\right)=0.92\right]$ and afternoon $\left(\mathrm{R}^{2}=0.96\right)$. The second algorithm was able to estimate of the time it took for individual cows to return to the pen after being milked in the morning $\left(\mathrm{R}^{2}=0.98\right)$, but less so in the afternoon $\left(\mathrm{R}^{2}=0.67\right)$. This study illustrates how data from electronic systems used to assess feeding and lying behavior can be mined to estimate novel measures. New work is now required to improve the estimates of our algorithm for individuals, for example by adding data from other electronic monitoring systems on the farm.
\end{abstract}

Received July 6, 2016.

Accepted January 14, 2017.

${ }^{1}$ Corresponding author: nina@mail.ubc.ca
Key words: accelerometer, precision farming, cow comfort, welfare, behavior

\section{Technical Note}

An increasing number of modern dairy farms use electronic equipment to monitor behavior, including feeding and lying behavior. Simple radio frequency electronic monitoring systems (e.g., GrowSafe, GrowSafe Systems Ltd., Airdrie, AB, Canada) can be used to record the time that individual dairy cows spend at the feed bunk (DeVries et al., 2003b), and more sophisticated systems (e.g., Insentec, Hokofarm Group BV, Marknesse, Holland) can record individual feed and water intake in addition to time spent eating (Chapinal et al., 2007; Montanholi et al., 2010). Accelerometers that record $g$-force acceleration (e.g., Hobo Pendant G, Onset Computer Corporation, Bourne, MA, or IceTag Sensor IceRobotics Ltd., Edinburgh, UK) can be used to record lying times of dairy cows (Ledgerwood et al., 2010; Gibbons et al., 2012; Medrano-Galarza et al., 2012), dairy calves (Bonk et al., 2013), and dairy goats (Zobel et al., 2015).

Sometimes the data collected by electronic equipment can provide information about activities for which the equipment was not originally intended. For example, Huzzey et al. (2014) developed an algorithm to identify competitive replacements at the feeder (in which one cow displaces another from the feeder) using feeding behavior data collected by the Insentec feeders. Similarly, electronic rumination monitoring systems (Hi-Tag, SCR Engineers Ltd., Netanya, Israel, and DairyCheck, BITSz Engineering GmbH, Zwickau, Germany) have been used to identify the onset of calving via acute decreases in rumination time (Schirmann et al., 2013; Büchel and Sundrum, 2014).

On most commercial dairy farms, cows must leave their pen 2 to 3 times a day to be milked. Cows typically spend between 0.5 and $6 \mathrm{~h} / \mathrm{d}$ walking to the parlor, queuing, being milked, and walking back to their pen (Espejo and Endres, 2007; Gomez and Cook, 2010). While out of the pen, cows cannot usually eat or lie down, potentially affecting behavior when they regain 
access to these resources (Metz, 1985). For example, after cows are prevented from lying down and eating for several hours a day, they spend more time lying and less time eating in the remaining proportion of the day (Munksgaard et al., 2005).

Furthermore, prolonged time away from the pen has been shown to be associated with lameness at both the group and individual level. Groups of cows that are away from their pen for longer durations have higher rates of lameness (Espejo and Endres, 2007). Also, individual cows tend to take longer to return to the pen when they were previously scored as lame (Juarez et al., 2003). Thus, recording the interval that cows do not have access to their pen could be useful for identifying lame cows.

In the majority of studies to date, the time cows spend away from their pen has not been recorded. The few studies that have measured time away typically use video recordings; however, video cameras can be difficult to install and video is time consuming to review. Here, we describe and test 2 novel algorithms designed to use information provided by electronic equipment (the Insentec electronic feeding system and Hobo Pendant $G$ data loggers) to estimate the time dairy cows spend away from their pen to be milked.

Our specific objectives were to (1) measure the ability of an algorithm to estimate the time cows spend away from the pen as a group to be milked and (2) measure the ability of another algorithm to identify the latency for individual cows to return to the pen following milking. Estimates generated by our algorithms were then compared with video recordings.

The 2 experiments for this study were conducted between July and November of 2013 at the University of British Columbia Dairy Education and Research Center (Agassiz, British Columbia, Canada). Cows were housed in a postpartum group pen containing 20 freestalls with deep bedded sand, 12 Insentec feed bins, and 2 Insentec water troughs. Stocking density was maintained at 20 cows in the pen. Fresh feed was delivered twice daily at approximately 0800 and 1600 $\mathrm{h}$ and cows were milked twice daily at approximately 0700 and $1700 \mathrm{~h}$. All algorithms were written in R programming language (version 3.2.2, The $\mathrm{R}$ Foundation for Statistical Computing, Vienna, Austria).

Panasonic WVBP330 video cameras (Panasonic Corp., Osaka, Japan) mounted approximately $8 \mathrm{~m}$ above the experimental pen were used to measure the time each cow left for and returned from milking. Unique alphanumeric symbols dyed on the hair on the back and sides of cows were used to identify them on video. The cameras were attached to a Panasonic video multiplexer (WV-FS416) and time-lapse recorder (AG6540p, Kadoma, Osaka Prefecture, Japan). Red lights
(100 W) were hung next to the cameras to facilitate video recording at night. A trained individual (A. J. Thompson) watched the video and recorded the time that cows exited and entered the pen as a group (i.e., the time the last cow exited the pen to be milked and the time the first cow entered the pen after being milked) and when focal individuals returned to the pen after being milked. Within 1 min, this individual had an intraobserver reliability of $100 \%$ agreement for groups $(\mathrm{n}=3 \mathrm{~d})$ and individuals $(\mathrm{n}=1$ cow for $3 \mathrm{~d})$. This was repeated with a different observer; this individual had an interobserver reliability of $100 \%$ agreement for groups $(\mathrm{n}=3 \mathrm{~d})$ and individuals $(\mathrm{n}=1$ cow for $3 \mathrm{~d})$. Agreement was calculated as a correlation using R.

The Insentec electronic feeding system was used to continuously monitor feeding activity. Each feed bin could hold approximately $40 \mathrm{~kg}$ of as-fed TMR, all feed bins were identical $(1.00 \mathrm{~m}$ wide, $0.50 \mathrm{~m}$ high, and 0.84 $\mathrm{m}$ deep), and all cows had access to all feed bins. Each cow had a unique passive transponder (High Performance ISO Half Duplex Electronic IDTag, Allflex, St. Hyacinthe, Quebec, Canada) attached to her ear tag. When a cow approached the bin, an antenna detected the cow's ear transponder, lowering the barrier and allowing the cow access to feed (Chapinal et al., 2007). When the gate opened, the Insentec system recorded the time. When the cow finished eating and left the bin, the barrier closed and the Insentec system again recorded the time. The Insentec system also recorded the cow number, bin number, feeding duration, and amount of TMR consumed for each visit. The data collected from electronic feed bins were used to identify the last time a cow exited any bin before leaving to be milked and the first time a cow entered any bin after returning from being milked.

Lying behavior was recorded at 1-min intervals using the Hobo Pendant G data loggers attached horizontally to the inside hind leg of each individual cow (Ledgerwood et al., 2010). Attachment was done with a veterinary self-adherent bandage (Co-Flex, Andover Healthcare Inc., Salisbury, MA) and folded cloth to minimize any chafing. Loggers were replaced once per week to ensure complete data collection, attached to alternating legs each week. The data collected from the loggers were used to identify the first time an individual cow lay down once she had entered the pen after milking.

We developed an algorithm to determine the time cows spend away from their pen as a group to be milked. The Insentec feeding system was used to continuously monitor individual feeding behavior for all cows present in one pen for the month of July 2013. During this time, 2 cows were removed from the pen and 2 new cows were added to maintain stocking density at 20 cows/pen, so a total of 22 cows were monitored at some point in 
the month. Each day, the algorithm estimated the time cows left and returned to the pen in the morning and afternoon. The algorithm used the Insentec system to detect "silent" periods with no feeding activity for more than 10 min anytime between 0650 and $0800 \mathrm{~h}$ in the morning and 1640 and $1730 \mathrm{~h}$ in the afternoon. Preliminary video analysis showed that these times were the earliest and latest that cows were observed to exit the pen to be milked, and that cows never returned from milking in less than 10 min. The algorithm then extracted the last time any cow in the group was recorded as exiting a feed bin before the silent period, and then the first time any cow was recorded entering a feed bin after the silence in feeding activity. For each morning and afternoon, the difference between these events was used as the estimate for the time cows spent away from the pen:

$t_{2}-t_{1} \geq 10 \wedge t_{1} \in \mathbb{N}\left\{410<t_{1}<480 \vee 1,000<t_{1}<1,050\right\} \rightarrow$ $T A=t_{2}-t_{1}$,

where $T A$ is the estimate of the time a group of cows was away from the pen to be milked in minutes, $t_{1}$ is the time when the cow that was most recently feeding exited a feed bin, and $t_{2}$ is the time the next cow entered a feed bin.

Estimates generated by our algorithm were then compared with times captured from the video recordings using linear regression. On one day, a subset of the full group of cows was observed returning to the pen shortly after leaving to be milked on video. The cows were quickly removed from the pen; however, because they had been away for less than $10 \mathrm{~min}$ and the cows ate when they returned to the pen, the algorithm generated an incorrect leaving estimate. This data point was excluded from the final analysis. On $5 \mathrm{~d}$ data from the electronic feeding system or video recordings were unavailable, so the remaining $26 \mathrm{~d}$ were used in the final analysis.

As determined by video, the average daily time away from the pen was $56 \pm 4$ min with a mean $30 \pm 2$ min away in the morning and $26 \pm 3 \mathrm{~min}$ in the afternoon (mean $\pm 95 \%$ CI). These times were very similar to the estimates generated by our algorithm for the morning $\left(33 \pm 3 \mathrm{~min} ; \mathrm{R}^{2}=0.92\right)$, afternoon $\left(29 \pm 3 \mathrm{~min} ; \mathrm{R}^{2}=\right.$ $0.96)$, and entire day $\left(62 \pm 4 \mathrm{~min} ; \mathrm{R}^{2}=0.93\right.$; Figure 1$)$. The algorithmic estimates for when groups exited and entered the pen were also closely correlated with the results from video recordings (Table 1; Figure 2).

Time away given by both the video recordings and algorithmic estimates are shorter than previously reported times spent out of the pen to be milked (Espejo and Endres, 2007; Gomez and Cook, 2010). This may
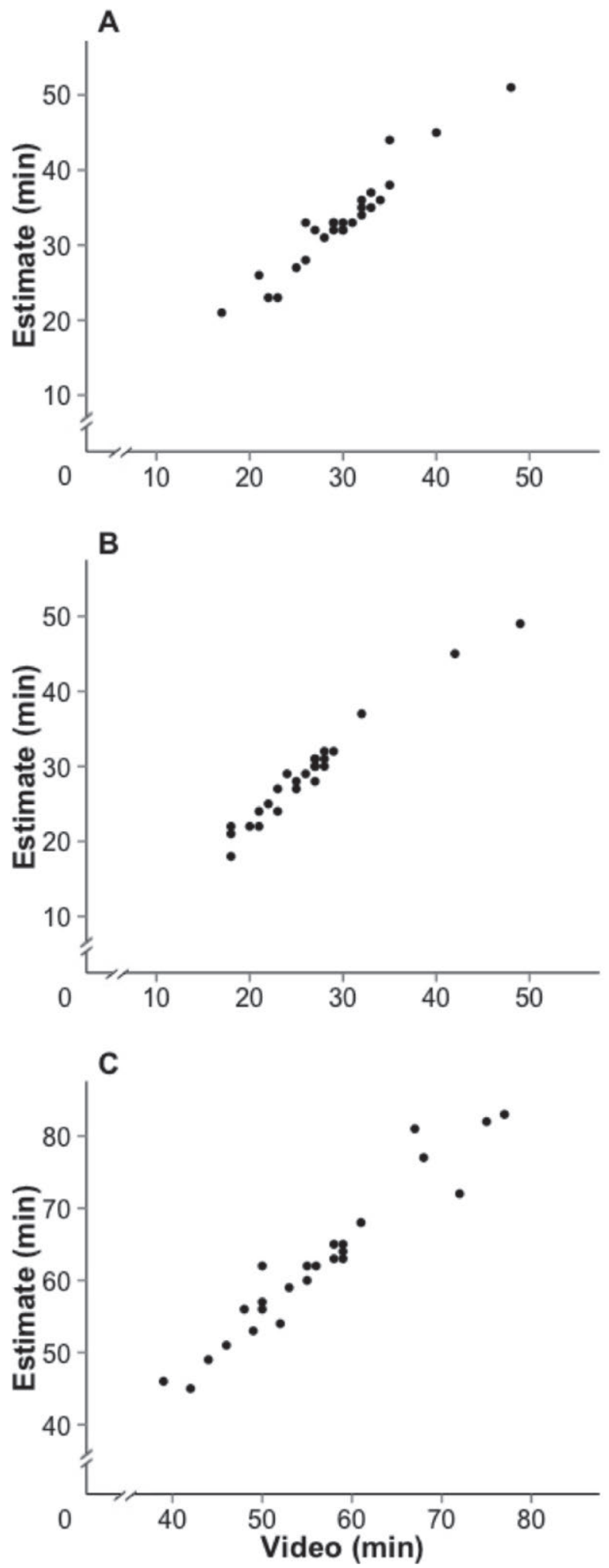

Figure 1. The correlation between video recordings and the algorithmic estimate for the daily time away from the pen as a group in the morning ( $\mathrm{A}, \mathrm{R}^{2}=0.92 ; \mathrm{n}=25$ milking events), afternoon $\left(\mathrm{B}, \mathrm{R}^{2}\right.$ $=0.96 ; \mathrm{n}=26$ milking events $)$, and entire day $\left(\mathrm{C}, \mathrm{R}^{2}=0.93 ; \mathrm{n}=25\right.$ complete days) to be milked. The algorithm used feeding data alone to estimate the time cows spend away from the pen. 
Table 1. The average time of day that cows left and returned to the pen as a group to be milked in the morning and afternoon given by video and estimated by an algorithm using feeding data (mean $\pm 95 \%$ CI)

\begin{tabular}{lcc}
\hline & \multicolumn{2}{c}{ Method } \\
\cline { 2 - 3 } Event & Video & Estimate \\
\hline Morning $^{1}(\mathrm{~h})$ & $0734 \pm 3$ & $0732 \pm 3$ \\
Exit time & $0804 \pm 3$ & $0806 \pm 4$ \\
Entry time & $1712 \pm 4$ & $1710 \pm 4$ \\
Afternoon & \\
Exit time & $1738 \pm 4$ & $1740 \pm 4$ \\
Entry time & & \\
\hline
\end{tabular}

${ }^{1} \mathrm{n}=26$ milking events; due to an error in the cows leaving the pen one morning, the leaving data of one morning milking event were discarded.

${ }^{2} \mathrm{n}=26$ milking events.

be because our pen size was smaller compared with the pen size used in both other studies. The difference in time away found here might also be a result of the way in which the algorithm is designed, which is to determine the last time a cow exited the pen and the first time a cow entered the pen after being milked. This tells us the minimum time cows were definitively away from the pen, but does not necessarily reflect the time an individual cow was away from the pen for milking. Determining individual differences in time away may be useful to identify sick or lame cows (Juarez et al., 2003). The cows in this experiment left the pen as a group, but had some flexibility in the time they were able to return.

The algorithm was able to reliably estimate the time that cows leave and return to the pen in both the morning and afternoon. The algorithm was also able to give a good estimate of the minimum amount of time that cows spend away from the pen to be milked. The estimates generated by our first algorithm were considered sufficiently robust to be used as a part of our second algorithm.

Next, we developed an algorithm to estimate the latency for individual cows to return to the pen after being milked. The Insentec feeding system and Hobo Pendant $\mathrm{G}$ data loggers were used to continuously monitor individual feeding and lying behavior of 12 healthy Holstein cows (6 primiparous and 6 multiparous) from parturition to 21 DIM, randomly selected between July and November of 2013. The return time given by our first algorithm was regarded as time zero or the starting point from which latency to return to the pen was calculated [the estimate was highly correlated $\left(\mathrm{R}^{2}=\right.$ 0.99) with video in both the morning and afternoon]. The new algorithm estimated the time individual cows returned to the pen using information from the Insentec feeding system, the Hobo data loggers, and a combina- tion of both technologies. These technologies were used to identify the first time the focal individual ate or lay down after being milked, and this value was used as the stop point in the calculation of latency. The difference between this individual return estimate and the group return estimate was considered as the latency to enter the pen after being milked (i.e., the time it takes for an individual to enter the pen after the first cow returned):

$$
L a t=t_{e}-t_{0},
$$

where Lat is the latency for an individual to return to the pen, $t_{e}$ is the estimate of the time the focal individual returned to the pen, and $t_{0}$ is the time that the first cow returned to the pen.

We developed 3 versions of this algorithm to determine the most effective estimate of latency: (1) using only feeding behavior, (2) using only lying behavior, and (3) using both feeding and lying behavior. First, using the Insentec system the new algorithm determined the earliest time that each individual cow was recorded feeding after time zero. Second, using the Hobo data loggers, the new algorithm identified the earliest time individual cows lay down after time zero. For the third version of the algorithm, if the time given by the data loggers was earlier than the time given by the feeding system, then this value was used. Otherwise, the Insentec system was used to estimate the individual return time.

Estimates generated by each version of this algorithm were then compared with return times observed on video using linear regression. On one occasion, a cow was recorded transitioning to lying before the group had returned to the pen from being milked. This could have been an error generated by the data logger, or the cow may have chosen to lie down in the alley or holding area for the parlor. This data point was excluded from the final analysis. On 64 occasions in the morning and 59 occasions in the afternoon, video recordings, data logger, or electronic feeding system data were unavailable, so the remaining 188 data points in the morning and 193 data points in the afternoon were used in the final analysis (total possible data points $=12$ cows, 21 d each, 2 milkings per day, 502 data points).

As determined from the video recordings, the average extra time that cows took to return to the pen from being milked, relative to the first cow (i.e., individual latency to return to the pen), was $37 \pm 5 \mathrm{~min}$ in the morning and $13 \pm 2 \mathrm{~min}$ in the afternoon. The difference in time taken to return to the pen in the morning and afternoon may be explained by routine health checks that were performed on postpartum cows in the morning. Every 3 d, postpartum cows were sorted into 
a holding pen after milking to be checked for metritis. These cows were unable to return to their home pen until the health check was completed.

When compared with video, the feeding behavior algorithm generated a good estimate for average individual latency to return to the pen in the morning (40 $\left.\pm 5 \mathrm{~min} ; \mathrm{R}^{2}=0.90\right)$, but not in the afternoon $(21 \pm 2$ $\min ; \mathrm{R}^{2}=0.31 ;$ Figure 3$)$. The quality of the estimate in the morning was likely because fresh feed delivery coincided with the time cows were away for morning milking. Previous work has shown that cows are highly motivated to feed following feed delivery (DeVries et al., 2003a; DeVries and von Keyserlingk, 2005). In contrast, fresh feed delivery occurred before cows left the
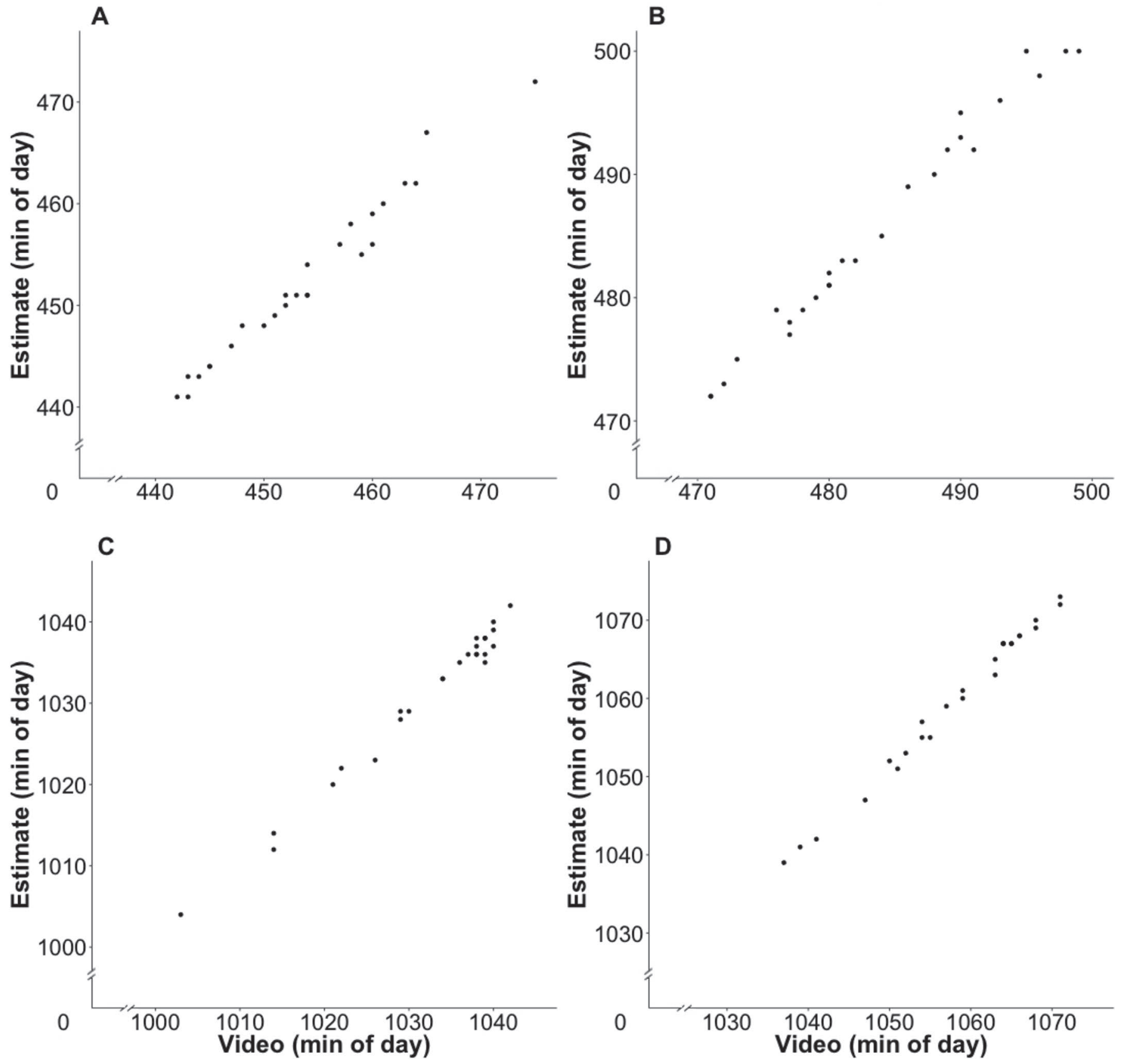

Figure 2. The correlation between video recordings and the algorithmic estimate for the daily $(\mathrm{n}=26 \mathrm{~d})$ time of day that cows left for and returned from milking as a group in the morning $\left(A, R^{2}=0.97 ; B, R^{2}=0.99\right)$ and in the afternoon $\left(C, R^{2}=0.99 ; D, R^{2}=0.99\right)$, respectively. The algorithm used feeding data alone to estimate the time of day that cows exit and enter the pen. 

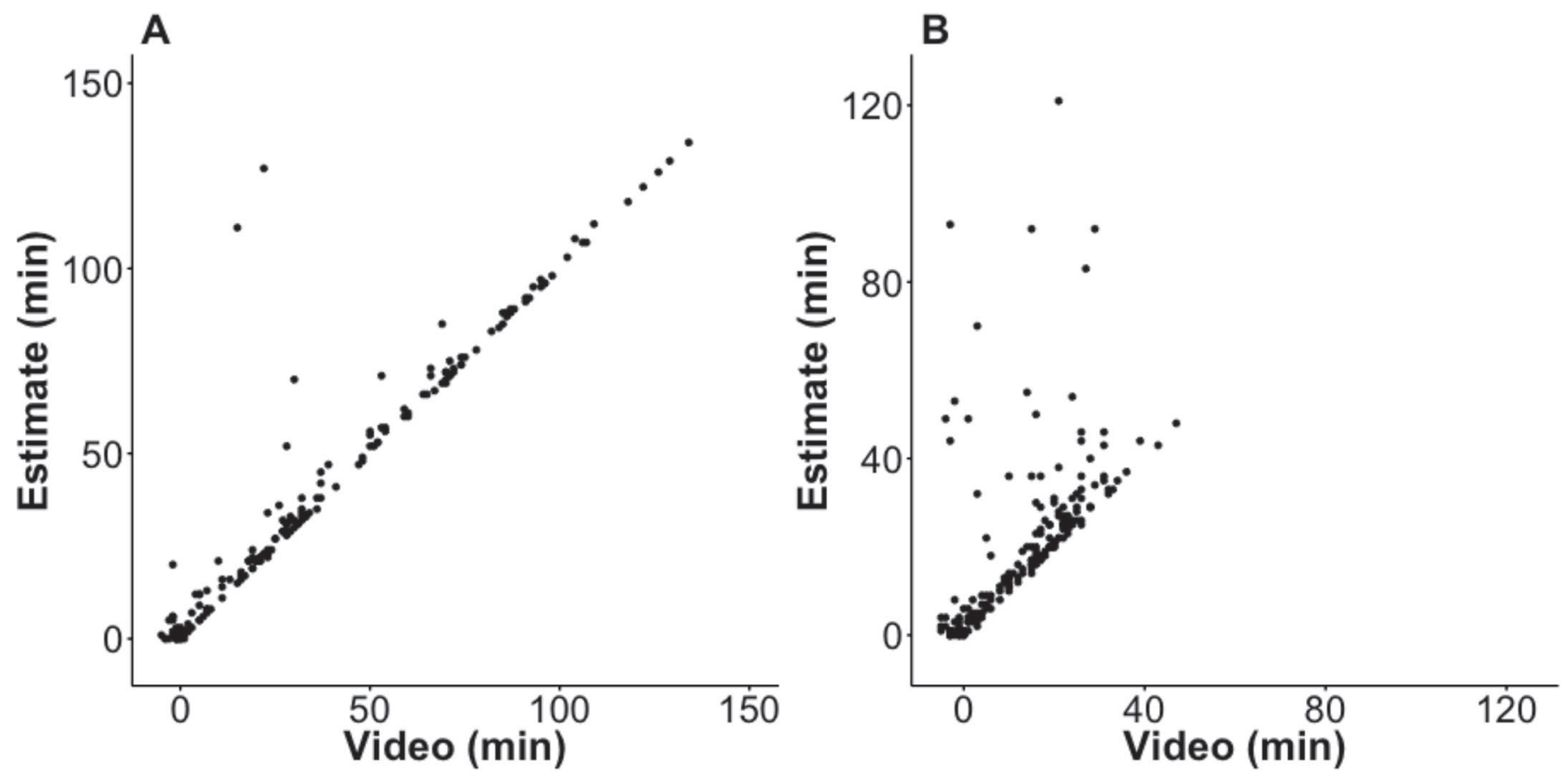

Figure 3. The correlation between video recordings and the algorithmic estimate for the time it takes for individual cows to return to their pen after being milked (i.e., after the first cow has returned to the pen) in the morning $\left(\mathrm{A}, \mathrm{R}^{2}=0.90\right)$ and afternoon $\left(\mathrm{B}, \mathrm{R}^{2}=0.31\right)$. The algorithm used feeding data alone to estimate the time of day that focal cows returned from milking. Total data points in the morning $=188$. Total data points in the afternoon $=193$.

pen to be milked in the afternoon. Thus, cows were likely less motivated to feed after returning to the pen in the afternoon.

The bulk of the estimates were within a few minutes of the return time measured using video; however, we did note a few outliers in the morning and afternoon. Video analysis confirmed that these were instances when the cow entered the pen and went to lie down or stood idle in the pen instead of going to eat.

Using lying behavior alone, the algorithm generated a poor estimate for average individual latency to return to the pen in both the morning $\left(101 \pm 7 \mathrm{~min} ; \mathrm{R}^{2}=\right.$ $0.39)$ and afternoon $\left(99 \pm 9 \mathrm{~min} ; \mathrm{R}^{2}=0.046\right.$; Figure 4$)$ when compared with video. Our results indicate that using lying data alone does not provide a good estimate of individual latency to return to the pen; cows appear to be more likely to engage in other activities within the pen before lying down. However, lying data could be used to improve estimates in the few instances when video analysis identified cows that lay down before going to eat.

The average estimated time for individual cows to return to the pen was $39 \pm 5$ min in the morning and $18 \pm 2 \mathrm{~min}$ in the afternoon using this combined algorithm (Figure 5). The estimates correlated well with the individual latency measured using video in the morning $\left(\mathrm{R}^{2}=0.98\right)$, but less so in the afternoon $\left(\mathrm{R}^{2}=\right.$
0.67). Incorporating the lying data into the algorithm improved the estimate over that based upon feeding time alone. However, the outliers removed by combining data did not result in a reliable estimate for the afternoon milking, likely because some cows entered the pen and stood idle. These cows could not be captured using this algorithm.

An algorithm based on feeding behavior measures from the Insentec system was able to provide a reliable pen-based estimate for the minimum time away for milking. The feeding behavior measures also provided a good estimate of individual times away from the pen in the morning, but not in the afternoon. The estimates in the morning and afternoon were both improved by adding lying behavior data from the Hobo loggers. Individual estimates were better for the morning milking than for the afternoon. The poor estimate in the afternoon was likely the result of cows being less motivated to eat when returning to the pen compared with the morning.

Combining information from multiple recording devices increases the chance of missing values. Indeed, combining the feeding and the lying behavior data resulted in missing estimates for approximately $25 \%$ of the observations. It is possible that our algorithm may have performed better with more complete data, and we encourage future work selecting technologies with 
A

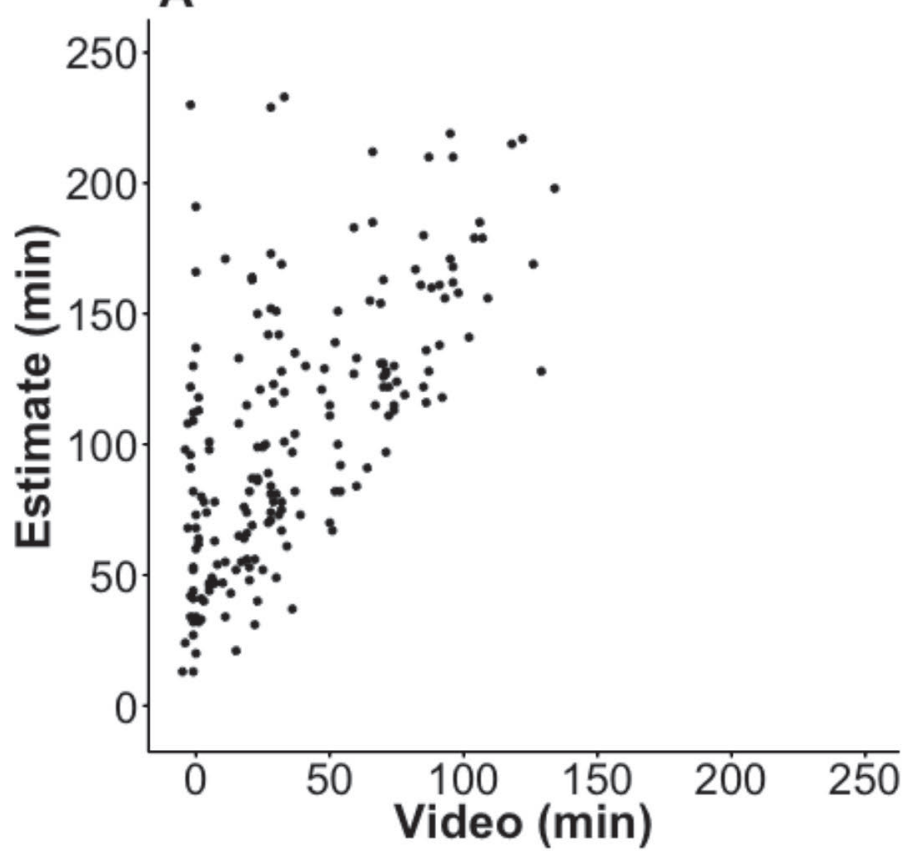

B

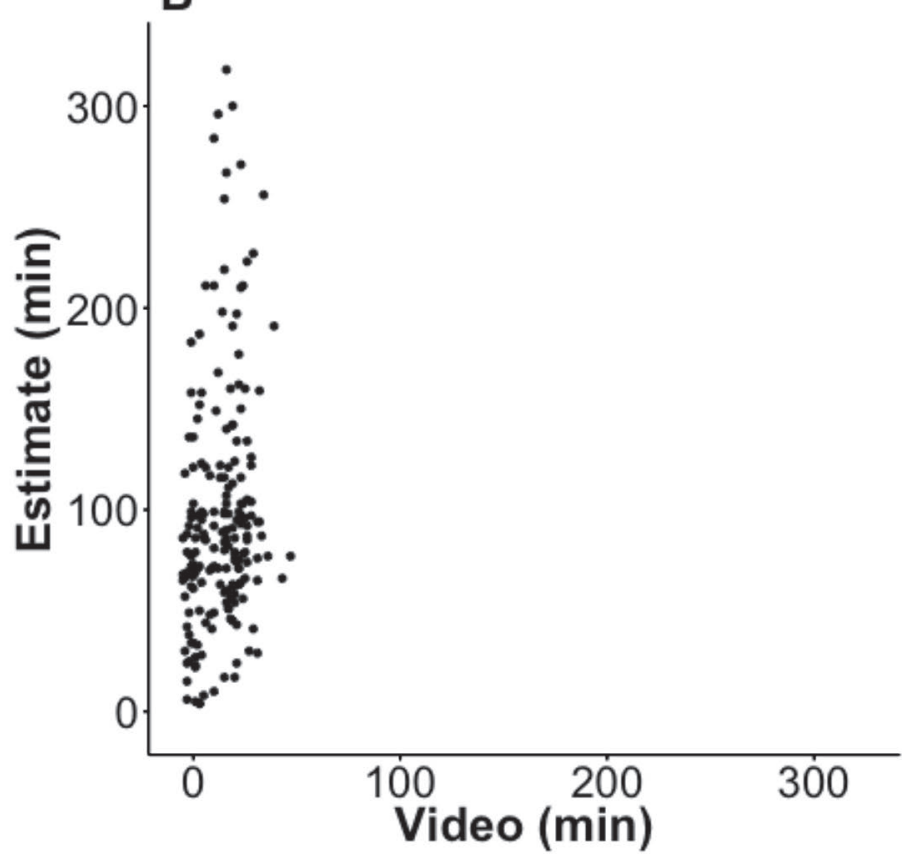

Figure 4. The correlation between video recordings and the algorithmic estimate for the time it takes for individual cows to return to their pen after being milked (i.e., after the first cow has returned to the pen) in the morning $\left(A, R^{2}=0.39\right)$ and afternoon $\left(B, R^{2}=0.046\right)$. The algorithm used lying data alone to estimate the time of day that focal cows returned from milking. Total data points in the morning $=188$. Total data points in the afternoon $=193$.
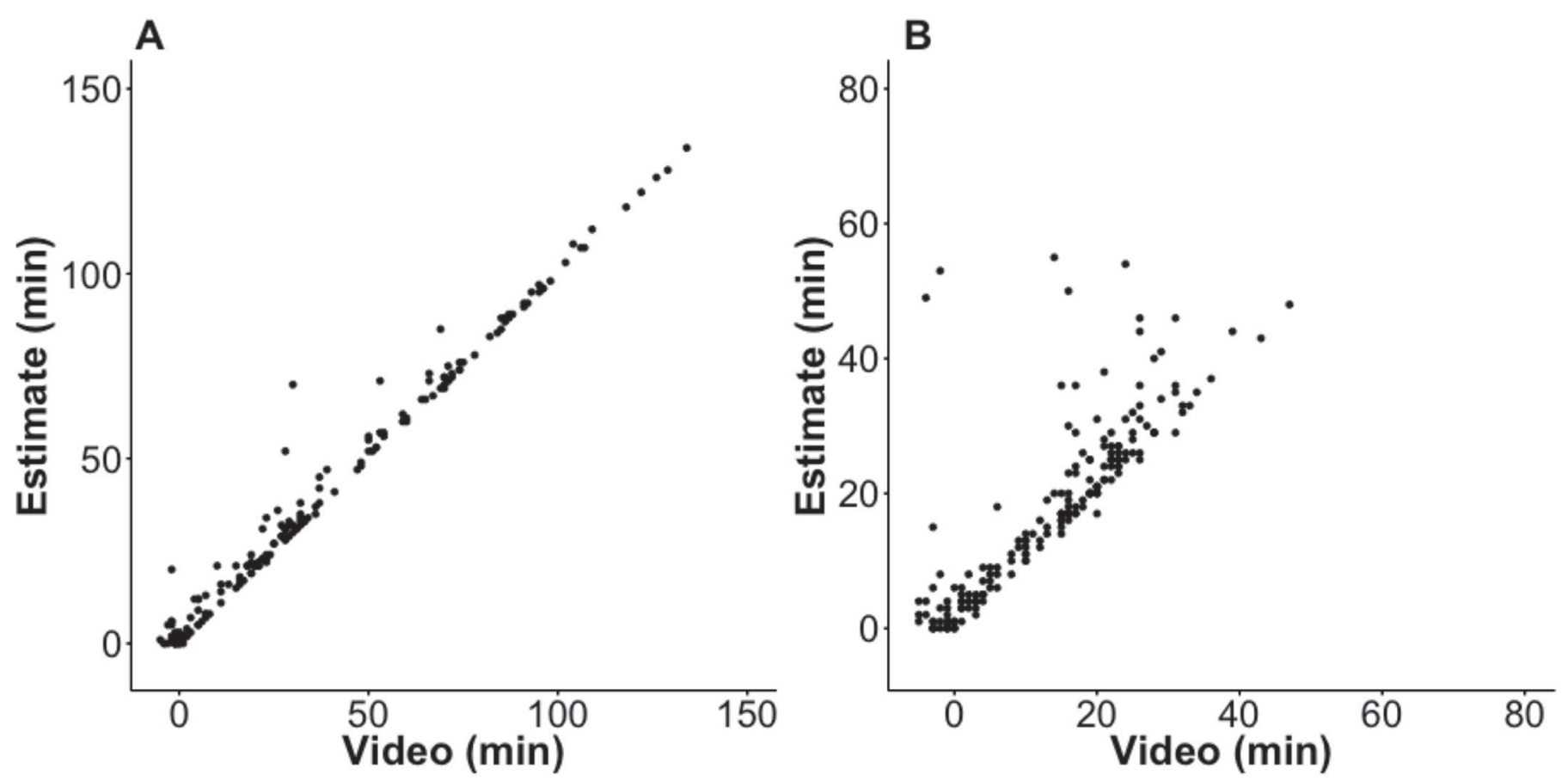

Figure 5. The correlation between video recordings and the algorithmic estimate for the time it takes for individual cows to return to their pen after being milked (i.e., after the first cow has returned to the pen) in the morning $\left(A, R^{2}=0.98\right)$ and afternoon $\left(B, R^{2}=0.67\right)$. The algorithm used a combination of feeding and lying data to estimate the time of day that focal cows returned from milking. Total data points in the morning $=188$. Total data points in the afternoon $=193$. 
combined low error rates including other commercially available monitoring systems for lying time and feeding behavior. In addition, radio-frequency identification (RFID) readers at the entryway of the pen could be used to directly record when cows enter and exit the pen.

\section{ACKNOWLEDGMENTS}

We thank the staff and students of the University of British Columbia (UBC) Dairy Education and Research Centre who helped with data collection in this experiment. Also, we thank Julia Lomb for kindly offering her Insentec, Hobo, and video data for this project. Funding for UBC's Animal Welfare Program comes from an Natural Sciences and Engineering Research Council of Canada Industrial Research Chair with industry contributions from the Dairy Farmers of Canada (Ottawa, ON, Canada), British Columbia Dairy Association (Burnaby, BC Canada), Westgen Endowment Fund (Milner, BC, Canada), Intervet Canada Corporation (Kirkland, QC, Canada), Novus International Inc. (Oakville, ON, Canada), Zoetis (Kirkland, QC, Canada), BC Cattle Industry Development Fund (Kamloops, BC, Canada), Alberta Milk (Edmonton, AB, Canada), Valacta (St. Anne-de-Bellevue, QC, Canada), and CanWest DHI (Guelph, ON, Canada).

\section{REFERENCES}

Bonk, S., O. Burfeind, V. S. Suthar, and W. Heuwieser. 2013. Technical note: Evaluation of data loggers for measuring lying behavior in dairy calves. J. Dairy Sci. 96:3265-3271.

Büchel, S., and A. Sundrum. 2014. Short communication: Decrease in rumination time as an indicator of the onset of calving. J. Dairy Sci. 97:3120-3127.

Chapinal, N., D. M. Veira, D. M. Weary, and M. A. G. von Keyserlingk. 2007. Technical note: validation of a system for monitoring individual feeding and drinking behavior and intake in grouphoused cattle. J. Dairy Sci. 90:5732-5736.
DeVries, T. J., and M. A. G. von Keyserlingk. 2005. Time of feed delivery affects the feeding and lying patterns of dairy cows. J. Dairy Sci. 88:625-631.

DeVries, T. J., M. A. G. von Keyserlingk, and K. A. Beauchemin. 2003a. Short communication: Diurnal feeding pattern of lactating dairy cows. J. Dairy Sci. 86:4079-4082.

DeVries, T. J., M. A. G. von Keyserlingk, D. M. Weary, and K. A. Beauchemin. 2003b. Technical note: Validation of a system for monitoring feeding behavior of dairy cows. J. Dairy Sci. 86:35713574 .

Espejo, L. A., and M. I. Endres. 2007. Herd-level risk factors for lameness in high-producing Holstein cows housed in freestall barns. J. Dairy Sci. 90:306-314.

Gibbons, J., C. Medrano-Galarza, A. M. de Passillé, and J. Rushen. 2012. Lying laterality and the effect of IceTag data loggers on lying behaviour of dairy cows. Appl. Anim. Behav. Sci. 136:104-107.

Gomez, A., and N. B. Cook. 2010. Time budgets of lactating dairy cattle in commercial freestall herds. J. Dairy Sci. 93:5772-5781.

Huzzey, J. M., D. M. Weary, B. Y. F. Tiau, and M. A. G. von Keyserlingk. 2014. Automatic detection of social competition using an electronic feeding system. J. Dairy Sci. 97:2953-2958.

Juarez, S. T., P. H. Robinson, E. J. DePeters, and E. O. Price. 2003 Impact of lameness on behavior and productivity of lactating Holstein cows. Appl. Anim. Behav. Sci. 83:1-14.

Ledgerwood, D. N., C. Winckler, and C. B. Tucker. 2010. Evaluation of data loggers, sampling intervals, and editing techniques for measuring the lying behavior of dairy cattle. J. Dairy Sci 93:5129-5139.

Medrano-Galarza, C., J. Gibbons, S. Wagner, A. M. de Passillé, and J. Rushen. 2012. Behavioral changes in dairy cows with mastitis. J. Dairy Sci. 95:6994-7002.

Metz, J. 1985. The reaction of cows to a short-term deprivation of lying. Appl. Anim. Behav. Sci. 13:301-307.

Montanholi, Y. R., K. C. Swanson, R. Palme, F. S. Schenkel, B. W McBride, D. Lu, and S. P. Miller. 2010. Assessing feed efficiency in beef steers through feeding behavior, infrared thermography and glucocorticoids. Animal 4:692-701.

Munksgaard, L., M. B. Jensen, L. J. Pedersen, S. W. Hansen, and L. Matthews. 2005. Quantifying behavioural priorities - effects of time constraints on behaviour of dairy cows, Bos taurus. Appl. Anim. Behav. Sci. 92:3-14.

Schirmann, K., N. Chapinal, D. M. Weary, L. Vickers, and M. A. G. von Keyserlingk. 2013. Short communication: Rumination and feeding behavior before and after calving in dairy cows. J. Dairy Sci. 96:7088-7092.

Zobel, G., D. M. Weary, K. Leslie, N. Chapinal, and M. A. G. von Keyserlingk. 2015. Technical note: Validation of data loggers for recording lying behavior in dairy goats. J. Dairy Sci. 98:1082-1089. 